\title{
Método QFD como Ferramenta para Desenvolvimento Conceitual de Produtos de Madeiras da Amazônia
}

\author{
Fernando Cardoso LUCAS FILHO ${ }^{1}$, Nabor da Silveira PIO $^{2}$, Daniel Rodrigues FERREIRA ${ }^{3}$ \\ RESUMO \\ O setor moveleiro caracteriza-se como um segmento que oferta produtos de diferentes formas e matérias-primas e estes produtos \\ precisam ter diferenciais para se destacar e atrair o interesse do consumidor. Em Manaus, o comércio de moveis encontra-se \\ num estágio considerado em evolução, podendo notar nos produtos ofertados, a total ausência de características que despertem \\ o interesse de compra nos consumidores. Seguindo este contexto, este artigo tem como objetivo apresentar preferências em \\ termos de produtos de madeiras da Amazônia dos consumidores de três classes econômicas - A1, B2 e C residentes na cidade \\ de Manaus e a aplicação da primeira matriz (casa da qualidade) do método QFD para definição dos conceitos dos produtos \\ identificados como preferidos pelas classes econômicas analisadas. Os resultados revelaram que há pouca variação nas preferências \\ por tipos de produtos por classe econômica, propondo-se conceitualmente que os produtos incorporem os atributos tidos \\ como preferidos por cada uma das classes econômicas analisada. Conclusóes importantes: bom acabamento; design - estilo \\ contemporâneo; preferência por madeira maciça e não por painéis (MDF).
}

PALAVRAS-ChAVE: QFD - Setor Moveleiro - Produtos de Madeira - Madeira Amazônica - Móveis.

\section{QFD Method as a Tool for Conceitual Development of Amazonian Wood Products}

\begin{abstract}
The furniture industrial characterizes himself as a segment that offer products of different shapes and raw materials, and products they need to have differential to highlight and attract the interest of consumers. In Manaus, the furniture industrial is considered a stage in evolution and may note in the products offered, the total absence of characteristics that chord in the interest of consumers purchase. In this context, this article aims to provide preferences in terms of timber products to the Amazon of consumers of three economic class - A1, B2 and C residents in the city of Manaus and implementation of the Mother of the quality of QFD method for defining the concepts of products identified as the preferred economic classes analyzed. The results showed that there is little variation in preferences for types of products by economic class, and proposed to conceptually that products incorporating the attributes taken as preferred by each of the classes economic review.
\end{abstract}

KEYWORD: QFD - Furniture Industry - Wood Products - Amazonian wood - piece of furniture

1 Universidade Federal do Amazonas - UFAM. Av. General Rodrigo Octávio Jordão Ramos, 3000, Campus Universitário, Coroado I - Manaus/Amazonas. E-mail: fecarlu@ufam.edu.br

2 Universidade Federal do Amazonas - UFAM. Av. General Rodrigo Octávio Jordão Ramos, 3000, Campus Universitário, Coroado I - Manaus/Amazonas. E-mail: nspio@ufam.edu.br

${ }^{3}$ Universidade Federal do Amazonas - UFAM. Av. General Rodrigo Octávio Jordão Ramos, 3000, Campus Universitário, Coroado I - Manaus/Amazonas. E-mail: danielrf@hotmail.com 


\section{INTRODUÇÃO}

O Brasil possui uma das maiores reservas de florestas tropicais do mundo, com 280 milhóes de hectares. Respondendo por mais de 30\% do estoque de carbono existente na vegetaçáo no mundo, as reservas de madeira da floresta Amazônica estão estimadas hoje em cerca de 50 bilhôes de $\mathrm{m}^{3}$, sendo $30 \%$ possível de serem comercializadas de forma racional, o que representa aproximadamente $50 \%$ do estoque de madeira tropical existente no mundo (REMADE, 2000).

Em decorrência dessa grande oferta de madeira, o setor de base florestal é normalmente analisado considerando dois grandes segmentos: polpa e papel e produtos de madeira sólida e reconstituída. Este último englobando produtos do tipo serrados, laminados, chapas de madeira e produtos de maior valor agregado (molduras, portas, janelas, pisos, móveis e outros). Esta segmentação foi criada em função das diferenças entre os tipos de processos, tipos de matériasprimas e manejo das florestas, escala de produção, produtos e aplicaçôes (ABIMCI, 2003).

Segundo Gorini (2000) apesar de todas as restrições ao uso de madeiras maciças para a fabricação de produtos de maior valor agregado, os móveis continuam sendo um dos melhores fins para o uso da madeira seja ela de florestas nativas ou de florestas plantadas.

Dentro deste contexto, observou-se que a maioria das pesquisas realizadas na cidade de Manaus na área madeireira/ moveleira foram direcionadas para detectar as características das empresas existentes no setor em termos de infraestrutura, matéria-prima utilizada e produtos ofertados, não havendo ainda, pesquisas referentes à identificação das reais necessidades dos consumidores, para transformá-las em requisitos projetuais, ou mesmo pesquisas quanto ao desenvolvimento conceitual de produtos ou do design de forma a orientar a reestruturação da indústria moveleira local, permitindo que esta desenvolva vantagens competitivas agregando maior valor aos produtos.

Para identificação das melhores formas de se agregar valor aos produtos de madeira sólida, como móveis, é necessário compreender a interação entre as propriedades da madeira, os recursos utilizados para sua transformação em produtos manufaturados, as reais necessidades dos consumidores de tais produtos e a aplicação de métodos e técnicas para transformar essa necessidade em requisitos a serem incorporados nos produtos.

Dentro do contexto metodológico, o QFD (Quality Function Deployment) - desdobramento da função qualidade, pode contribuir para revelar a definição da qualidade demandada pelo consumidor para sua completa satisfaçáo em termos dos produtos a serem ofertados pela empresa.
Deste modo, para contribuir com a solução do problema exposto acima, essa pesquisa busca realizar uma aplicaçáo do método QFD como ferramenta para desenvolvimento de projeto conceitual de produtos de madeiras da Amazônia, a partir da identificação das reais necessidades dos consumidores de três classes econômicas de maior representatividade de modo a contribuir com a competitividade do setor moveleiro da cidade de Manaus.

\section{Panorama do Setor de Produtos de Madeira no Brasil}

A indústria de base florestal do Brasil apresenta uma das mais promissoras perspectivas de expansão do mundo, quer pelas condiçóes de clima e solo favoráveis para o plantio, como pelos crescentes investimentos em ampliação e modernização de seu parque fabril. Movimentando 3\% do PIB nacional (US\$ 20 bilhóes) esta indústria reúne segmentos distintos como produtos de madeira sólida (serrados, laminados, chapas de madeira e produtos de maior valor agregado), papel, celulose, construção civil e energia, que tem na floresta a sua base de matéria-prima. Hoje é representada por $30 \mathrm{mil}$ empresas, que oferecem emprego direto a 900 mil pessoas e geram US $\$ 4,5$ bilhôes em exportaçóes por ano (REMADE 2000).

De acordo com dados da Associação Brasileira da indústria do Mobiliário - ABIMOVEL (2005), a indústria brasileira de móveis é formada por mais de 16.112 micros, pequenas e médias empresas de capital nacional, em sua maioria, que geram mais de 189.372 empregos.

Segundo Coutinho (1999), a produção de móveis está geograficamente dispersa por todo território nacional, localizando-se principalmente na região centro-sul do país, que responde por $90 \%$ da produçáo nacional e $70 \%$ da mãode-obra do setor.

Para Gorini (2000), a competitividade da indústria moveleira pode ser ampliada significativamente nos próximos anos em função da adoçáo de novas tecnologias, novas matérias-primas, como a madeira manejada, design diferenciado, especialização da produção, estratégias comerciais e de distribuição. A dinâmica das inovaçóes baseiase, principalmente, naquelas que se referem ao produto, através do aprimoramento do design e da utilização de novos materiais. A qualidade do produto final é julgada de acordo com as seguintes variáveis principais: material, design e durabilidade.

\section{Características do Setor Moveleiro no Amazonas}

Quanto à realidade do setor moveleiro do Estado do Amazonas, de acordo com estudo de Silva et al. (2002), a maioria das movelarias são de micro porte, possui dificuldades de equipamentos, infra-estrutura, logística e carência de máo-de-obra especializada. Os principais fatores limitantes ao desenvolvimento do setor são, sobretudo, o acesso a novos mercados, leis ambientais que dificultam o acesso à matéria- 
prima, a falta de investimento em design e a falta de capital de giro.

Segundo dados do relatório do Projeto Floresta Viva (2006), o setor moveleiro de Manaus está desorganizado e bastante confuso, sendo composto na sua maioria por pequenas oficinas de fundo de quintal, sub-equipadas e com dificuldades financeiras. A oferta de móveis é muito homogênea, sendo estes muito parecidos em termos de design, de qualidade e de preço. A qualidade dos móveis pode ser aprimorada, principalmente em termos do design rústico e sobrecarregado que a maioria dos móveis apresenta. A principal matéria-prima utilizada pelas micros movelarias é o MDF e compensado, por ser mais fácil de trabalhar. A madeira maciça só é utilizada por estas movelarias quando se trata de móveis sob encomenda e por aquelas que possuem loja própria e tem um volume de produçấo mais estável.

Quanto à dificuldade na aquisição de madeira maciça, em virtude das restriçóes ambientais, certamente com a adoção de prática de manejo florestal sustentada, poder-se-ia atender a demanda interna por madeira utilizando-se apenas um pequeno percentual das áreas com potencial produtivo.

\section{Qualidade do Produto}

Para Gobe (2004), o termo qualidade refere-se a um conjunto que delineiam a essência, a natureza de um ser ou de uma coisa. Indica que algo pode se sobressair em relação a outros, sendo a qualidade, portanto, uma virtude. Segundo o autor, a qualidade do produto é definida em termos da capacidade de um produto para desempenhar suas funçôes; inclui a durabilidade geral do produto, sua confiança, precisão, facilidade de operação e vários outros atributos valiosos.

De acordo com Gorini (2000), qualidade é a totalidade dos atributos e características de um produto que afetam sua capacidade de satisfazer necessidades declaradas ou implícitas.

Segundo Baxter (2000), a qualidade do produto tem significados diferentes para diferentes pessoas. No entanto deve-se adotar uma postura mais abrangente para se definir a qualidade do produto. Deve-se considerar em primeiro lugar a percepção do consumidor sobre a tal qualidade.

Santos (2000) diz que qualidade do produto é adequação ao uso. Se determinado produto é adequado ao uso que se propóe, logo ele tem qualidade. Todavia, essa adequação ao uso atinge diversos níveis e pode ser interpretada de diversas maneiras.

De acordo com Cheng \& Melo Filho (2007), para avaliar a qualidade do produto pode se adotar o modelo proposto por Noriaki Kano (figura 1).

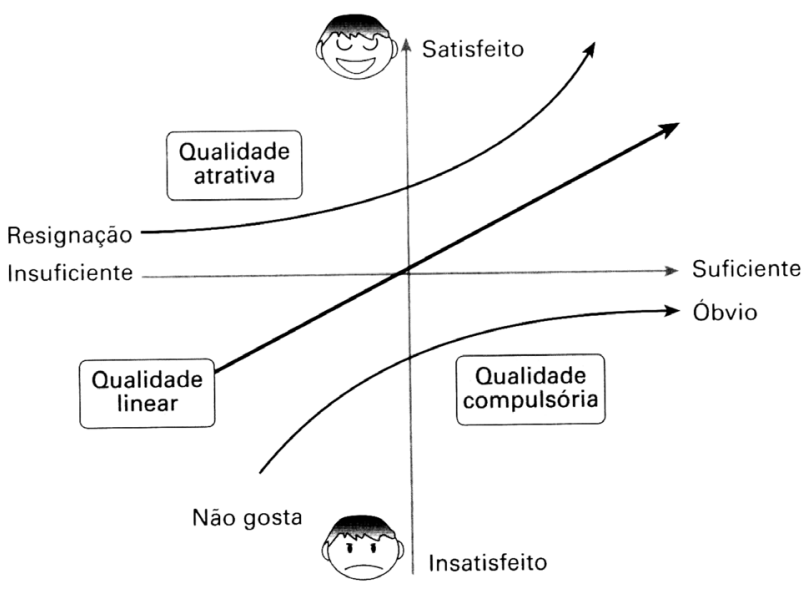

Figura 1 - Relação entre satisfação do cliente e nível de desempenho do produto.

Fonte: Kano apud Cheng \& Melo Filho (2007)

Este modelo é útil para classificação dos diversos requisitos de qualidade do produto conforme percebidos pelos consumidores:

a) Requisitos de qualidade linear ou requisitos com desempenho esperado: são requisitos de qualidade que trazem maior satisfação aos clientes, à medida que aumenta o nível de desempenho do produto.

b) Requisitos de qualidade óbvia, compulsória ou obrigatória: são aqueles considerados óbvios, quando o desempenho é suficiente, porém sua ausência ou insuficiência provoca insatisfação. Estão relacionados com as necessidades básicas dos clientes que pressupõem que o produto as satisfaz. Para Baxter (2000) a ausência das qualidades básicas provoca uma grande insatisfação, enquanto a sua presença é considerada como uma coisa normal e não contribui para aumentar o sentimento de satisfação.

c) Requisitos de qualidade atrativa: refere-se às qualidades que mesmo com desempenho insuficiente são aceitos com resignação pelos consumidores. Porém, a suficiência ou presença traz grande satisfação. Estão relacionados com as necessidades que, se fossem satisfeitas pelo produto, surpreenderiam e encantariam os clientes. Baxter (2000) chama essas qualidades de fatores de excitação.

Amaral et al. (2006) concluíram que o diagrama de Kano mostra a necessidade continua de achar novos requisitos que excitam/ impactam os clientes. 


\section{QFD - (Quality Function Deployment)}

QFD (Quality Function Deploymen) é traduzido para o português como desdobramento da função qualidade, e trata-se de uma metodologia que busca traduzir e transmitir as informaçôes necessárias para que o produto desenvolvido atenda as necessidades dos clientes, por intermédio de desdobramentos sistemático, iniciando-se com a determinação da voz do cliente, passando por todos os fatores necessários para o desenvolvimento do produto (CHENG \& MELO FILHO, 2007).

QFD é a conversão dos requisitos do consumidor em características de qualidade do produto e o desenvolvimento da qualidade de projeto para o produto acabado através de desdobramentos sistemáticos das relaçóes entre os requisitos do consumidor e as características do produto. (AKAO, apud PEIXOTO \& CARPINNETTI, 1999).

De acordo com Miguel, citado por CHENG; MELO FILHO(2007) os setores de atuação das empresas que utilizam o QFD no Brasil são: setor automobilístico, eletrodomésticos, metalúrgica básica, produtos alimentícios, bebidas, fumo, máquinas e equipamentos e produtos químicos.

Os principais motivos que levam as empresas a iniciar a implantação do QFD foram: a) melhoria do processo de desenvolvimento de produtos; b) decisão a partir dos conhecimentos de suas vantagens; c) aumento da satisfação dos clientes.

Assim, diante desse contexto, este artigo tem como objetivo aplicar o método Q.F.D. para definir as necessidades e desejos em termos de produtos de madeiras da Amazônia dos consumidores de três classes econômicas - A1, B2 e C residentes na cidade de Manaus.

\section{METODOLOGIA}

Para identificar o perfil dos consumidores e as preferências em termos de produtos a base de madeira da Amazônia foram coletados dados a partir da aplicação de um questionário para 300 indivíduos, distribuídos nas três classes de maior representatividade econômica na cidade de Manaus, de acordo com dados do IBGE (2000). A descrição do perfil dos consumidores de cada uma das três classes econômicas analisadas foi feita a partir da interpretaçấo e análise das respostas aos questionários aplicados aos moradores da cidade de Manaus que atenderam ao critério de inclusão.

Foram aplicados 100 questionários por classe econômica, totalizando 300 questionários. A seleção dos entrevistados foi aleatória, buscando cobrir os potenciais consumidores de móveis de madeira na cidade de Manaus em cada uma das classes sociais estudadas. Os critérios para classificar os clientes de acordo com as classes sociais foram, grau de essolaridade, renda e grau de urbanizaçáo do bairro onde reside. A abordagem da pesquisa para aplicação do questionário buscou identificar dentre os clientes, aqueles que buscavam comprar ou estavam realizando pesquisas com intensão de compra de móveis de madeira nas lojas e centros comerciais shoppings do ramo. Os locais de aplicação dos questionários foram os centros comerciais e lojas que comercializam móveis de alto padrão para representar a classe $\mathrm{A} 1$ e lojas de bairros das zonas centro-oeste, sul e centro-sul da cidade para para representar os clientes pertecentes a classe econômica B2 e lojas de comércio varejistas de móveis das zonas leste e norte da cidade para representar a Classe C.

As classes sociais que compóem a amostra são:

- Classe econômica A1, representada pelos indivíduos maiores de 18 anos que ganham acima de 20 salários mínimos (25,4\% da população de Manaus);

- Classe econômica B2, representada pelos indivíduos maiores de 18 anos que ganham entre 5 à 10 salários mínimos (22,5\% da população de Manaus) e;

- Classe econômica C, representada pelos indivíduos maiores de 18 anos que ganham de 2 a 5 salários mínimos ( $25 \%$ da população de Manaus).

O questionário foi construído em blocos temáticos obedecendo a uma ordem lógica na elaboração das perguntas, cujo roteiro contém perguntas mistas, incluindo perguntas abertas (respostas livres), fechadas (duas opçóes), e de múltipla escolha (fechada com uma série de respostas possíveis). Os dados incluíram informaçóes sobre perfil do entrevistado, produtos consumidos, características dos produtos desejados e matéria-prima dos produtos. $\mathrm{O}$ instrumento de coleta de dados proporcionou uma interaçáo efetiva entre o informante e a pesquisa. Para facilitar o processo de tabulaçáo de dados por meio de suporte computacional, as questóes e suas respostas foram armazenadas em banco de dados e posteriormente utilizados na aplicaçáo do método QFD.

\section{Aplicação Método QFD}

Existem na literatura vários métodos para a aplicação do QFD, mas para esta pesquisa foi adotado a dos autores Cheng e Melo Filho (2007) por ser a mais completa e a mais voltada aos objetivos propostos na pesquisa. Nesta pesquisa foram contempladas apenas as tabelas de desdobramento da qualidade exigida e tabela de desdobramento das características da qualidade do produto para a construçáo da matriz da qualidade ou casa da qualidade.

As etapas seguidas adotadas para a aplicação do método QFD foram:

1. Identificação das necessidades dos consumidores das três classes econômicas A1, B2 e C, ou seja, captação da voz dos clientes, a partir da aplicação do questionário; 
2. Conversão das vozes dos consumidores em qualidades exigidas;

3. Construção da tabela de desdobramento das qualidades exigidas;

4. Construção da tabela de desdobramento das características da qualidade;

5. Construçáo da matriz da qualidade ou casa da qualidade utilizando-se o software QFD Designer 5 da IDEA core.

\section{RESULTADOS E DISCUSSÕES}

\section{Perfil dos Consumidores Classes Econômicas A1, B2 e C}

A descrição do perfil dos consumidores de cada uma das três classes econômicas analisadas foi feita a partir da interpretação e análise das respostas aos questionários aplicados aos moradores da cidade de Manaus que atenderam ao critério de inclusão. Foram aplicados 100 questionários por classe econômica, totalizando 300 questionários.

Em relação ao perfil dos consumidores da classe econômica A1, constatou-se que dos 100 consumidores que responderam ao questionário:

- 65\% sáo do sexo feminino;

- 80\% são casados;

- 45\% estáo na faixa etária de 40 a 49 anos;

- 89\% têm renda acima de 7.600,00

- $65 \%$ são profissionais liberais

- 56\% são pós-graduados;

$-85 \%$ residem na zona centro-sul

- $95 \%$ comprariam produtos de madeira

Quanto ao perfil dos consumidores da classe econômica $\mathrm{B} 2$, constatou-se que dos 100 consumidores que responderam ao questionário:

$-60 \%$ são do sexo feminino;

- 45\% são separados;

- 52\% estáo na faixa etária de 40 a 49 anos;

- $100 \%$ têm renda entre $1.900,00$ a 3.800,00;

- 39\% são empresários;

- $41 \%$ são superior completo;

- 77\% residem na zona sul;

- $96 \%$ comprariam produtos de madeira.

Para os consumidores da classe econômica C, constatou-se que dos 100 consumidores que responderam ao questionário:

- $80 \%$ sáo do sexo masculino;

$-55 \%$ outros (amigados, viúvos, desquitados);

- $52 \%$ estáo na faixa etária de 52 a 59 anos;
- 100\% têm renda entre 760,00 a 1.900,00;

- 39\% são autônomos;

- 62\% Ensino médio completo;

$-41 \%$ residem na zona centro-oeste;

- 97\% comprariam produtos de madeira.

\section{Identificação das preferências dos Consumidores das Classes Econômicas A1, B2 e C}

Os dados obtidos quanto à preferência em termo de produtos dos consumidores da classe econômica A1 indicam que os produtos preferidos para compra são: cama (20\%), móveis para escritório (20\%), mesas para sala de jantar (10\%) e cadeiras (20\%).

De acordo com os dados obtidos os produtos preferidos pela classe B2 são: cama (20\%), guarda-roupa (13\%), cadeira $(12 \%)$, mesa sala jantar (12\%) e objetos de decoraçáo (12\%).

Os dados obtidos demonstram que dentre os produtos citados, os preferidos pela classe C para compra são: cama (23\%), guarda-roupa (20\%), cadeira (19\%), mesa sala jantar (23\%) e objetos domésticos (10\%).

Pode se constatar que as preferências das três classes são bastante parecidas, divergindo apenas quando se trata de móveis para escritório, que foi identificado como um dos produtos preferido pela classe $\mathrm{A} 1$, a que tem maior poder de compra. As classes $\mathrm{B} 2 \mathrm{e} \mathrm{C}$ divergem apenas em produtos para decoraçáo - preferidos pela classe B2 e objetos domésticos preferidos pela classe C.

Quando questionados quanto aos fatores que levariam a compra de um produto de madeira, os consumidores selecionaram três fatores de acordo com a importância e seguindo uma ordem de preferência pessoal. Este questionamento foi importante para se ter uma idéia dos principais fatores a serem priorizados durante a aplicação do método QFD.

Segundo os dados obtidos, os três fatores principais que levariam os consumidores da classe $\mathrm{A} 1$ comprar um produto de madeira são: $1^{\circ}$ design $(45 \%), 2^{\circ}$ qualidade $(28 \%)$ e $3^{\circ}$ preço $(22 \%)$.

Para os consumidores da classe $\mathrm{B} 2$, os três fatores principais que um produto de madeira deve ter para despertarem seu interesse de compra sáo: $1^{\circ}$ qualidade $(35 \%), 2^{\circ}$ conforto (30\%) e $3^{\circ}$ design (20\%).

Em se tratando dos consumidores da classe C, os três fatores principais que observam e priorizam em um produto de madeira na hora da compra são: qualidade $(31 \%)$, preço (30\%) e conforto (29\%).

Para reforçar o questionamento quanto aos fatores de compra, foi perguntado aos consumidores das três classes o que um produto de madeira deveria ter para ser considerado 
com qualidade, esse questionamento é de suma importância para saber as reais necessidades dos consumidores a serem utilizadas durante a construçáo da tabela de desdobramento da qualidade durante a aplicação do método QDF.

Os consumidores da classe A1 destacaram as seguintes características de qualidade dos produtos: ter matéria-prima de qualidade (isenta de defeitos) (30\%), ter bom acabamento $(30 \%)$, ter design inovador $(20 \%)$, ser adequado ao uso $(10 \%)$ e ser resistente (10\%). Aqui a resitência refere-se a capacidade re resistir aos esforços que a madeira é submetida em uso.

Para os consumidores da classe B2, as características de qualidade dos produtos são: ter bom acabamento ( $40 \%)$, ter design (35\%), ser de madeira maciça (8\%), ter formas simples (6\%), ser seguro (5\%), ter durabilidade (4\%) e ter estilo (2\%).

As respostas dos consumidores da classe $\mathrm{C}$ a essa resposta indicam as seguintes características de qualidade dos produtos: ter bom acabamento $(49 \%)$, ter qualidade $(19 \%)$, ter preço $(15 \%)$ ser confortável (10\%), ter estilo (5\%) e ter durabilidade (2\%).

Quanto ao estilo preferido nos móveis, o selecionado pelas três classes econômicas foi o estilo contemporâneo.

Portanto é importante que o setor moveleiro local se preocupe com a adoção de estilos que satisfaçam a preferência dos consumidores, pois segundo dados do relatório do Projeto Floresta Viva (2006) onde foi estudada a cadeia produtiva da madeira e móveis na cidade de Manaus, a oferta de móveis é muito homogênea, sendo estes muito parecidos em termos de design, de qualidade e de preço. A qualidade dos móveis pode ser aprimorada, principalmente em termos do design rústico e sobrecarregado que a maioria dos móveis apresenta.

Em se tratando de acabamento dos móveis de madeira, os resultados mostram que os preferidos pelas três classes econômicas são verniz fosco (mais de 60\%) ou acabamento encerado (mais de 20\%).

Quanto à satisfação dos consumidores em termos dos produtos ofertados atualmente na Cidade de Manaus ficou claro que mais de $90 \%$ de todos os entrevistados pertencentes as três classes econômicas analisadas não estão satisfeitos com os produtos de madeira ofertados.

No quesito estilo de madeira para a fabricação dos produtos, as preferências recaíram sobre: madeiras claras e madeiras leves para as classes A1 e B2 e madeiras leves e madeiras escuras para a classe $\mathrm{C}$.

O ultimo questionamento foi quanto à melhor combinação entre materiais para a fabricação dos produtos, sendo destacado:

a) Classe A1 - madeira maciça + metal;

b) Classe B2 - madeira maciça + metal ou vidro;

c) Classe $\mathrm{C}$ - madeira maciça + vidro.

\section{Aplicação do Método QDF para geração do projeto conceitual}

\section{Conversão das vozes dos consumidores em qualidades exigidas}

A primeira tabela desenvolvida foi a de conversão das vozes dos consumidores em qualidades exigidas a qual foi construída para cada uma das três classes econômicas separadamente a partir da conversão das preferências dos consumidores em qualidades exigidas de acordo com a linguagem projetual, as tabelas foram preenchidas sempre da esquerda para a direita e seus dados foram agrupados em dois níveis.

\section{Conversão das vozes dos consumidores da Classe $\mathbf{A} 1$ em qualidades exigidas}

A tabela 1 apresenta a conversão das principais necessidades dos consumidores da Classe A1 em qualidades exigidas nos produtos de madeira.

Tabela 1 - Conversão das vozes dos consumidores em qualidades exigidas Classe A1

\begin{tabular}{|c|c|}
\hline NECESSIDADES CLASSE A1 & QUALIDADES EXIGIDAS CLASSE A1 \\
\hline \multirow{5}{*}{ Ter design inovador } & Usar estilo contemporâneo \\
\hline & $\begin{array}{l}\text { Usar materiais mesclados como madeira } \\
\text { maciça e metal }\end{array}$ \\
\hline & Ter boa aparência \\
\hline & Ter aparência sofisticada - não ser rústico \\
\hline & Usar madeiras claras \\
\hline \multirow{4}{*}{ Ter bom acabamento } & Usar madeira seca para evitar rachaduras \\
\hline & Ter superfície suave ao toque \\
\hline & Usar verniz fosco ou cera \\
\hline & Destacar o desenho da madeira \\
\hline \multirow{4}{*}{ Ser fácil de usar } & Fácil de abrir \\
\hline & Fácil de fechar \\
\hline & Fácil de montar \\
\hline & Fácil de desmontar \\
\hline \multirow[b]{2}{*}{ Ter qualidade } & Usar madeira maciça de boa qualidade \\
\hline & $\begin{array}{c}\text { Usar acessórios e ferragens de boa } \\
\text { qualidade }\end{array}$ \\
\hline \multirow{3}{*}{ Fácil de Montar e desmontar } & Ter poucos sistemas e subsistemas \\
\hline & $\begin{array}{l}\text { Ter sistemas e subsistemas de fácil } \\
\text { montagem e desmontagem }\end{array}$ \\
\hline & Usar madeiras leves \\
\hline \multirow{3}{*}{ Ser confortável } & Possuir medidas adequadas ao usuário \\
\hline & Possuir formas confortáveis ao uso \\
\hline & $\begin{array}{c}\text { Ter acabamento que evite machucados no } \\
\text { usuário }\end{array}$ \\
\hline \multirow{2}{*}{ Ser resistente } & Usar acessórios que permitam boa fixação \\
\hline & Ser de madeira resistente \\
\hline
\end{tabular}

Fonte: 0 autor (2008)

Pode se observar que as principais necessidades dos consumidores da classe $\mathrm{A} 1 \mathrm{em}$ termos de produto de madeira sáo: ter design inovador, ter bom acabamento, ser fácil de usar, 
ter qualidade, ser fácil de montar e desmontar, ser confortável e ser resistente. Estas necessidades foram convertidas em qualidades exigidas que são: usar estilo contemporâneo, usar mais de um material na fabricação dos produtos como madeira e metal, usar madeiras claras, usar madeiras secas para evitar rachaduras - que é um dos principais problemas relatados, usar matéria-prima de qualidade, usar acabamento em verniz fosco ou cera, produtos devem ser fácil abrir e fechar, fácil de montar e desmontar, ser de madeira maciça e ser de madeira leve.

Em relação ao design, Coutinho (1999) diz ser o único fator de inovação próprio da indústria de móveis, que ao propiciar a diferenciaçấo do produto frente aos demais, se constitui em um dos elementos-chave para as condiçóes de concorrência neste setor.

\section{Conversão das vozes dos consumidores da Classe B2 em qualidades exigidas}

A tabela 2 apresenta a conversão das principais necessidades dos consumidores da Classe B2 em qualidades exigidas nos produtos de madeira.

Tabela 2 - Conversão das vozes dos consumidores em qualidades exigidas Classe B2

\begin{tabular}{|c|c|}
\hline NECESSIDADES CLASSE B2 & QUALIDADES EXIGIDAS CLASSE B2 \\
\hline \multirow{6}{*}{ Ter boa aparência } & Usar estilo contemporâneo \\
\hline & Usar forma simples \\
\hline & Ter design diferenciado \\
\hline & $\begin{array}{l}\text { Usar materiais mesclados como madeira } \\
\text { maciça e metal ou vidro }\end{array}$ \\
\hline & Usar madeiras claras \\
\hline & Usar madeira com cores diferentes \\
\hline \multirow{3}{*}{ Ter bom acabamento } & Usar madeira seca para evitar rachaduras \\
\hline & Ter superfície suave ao toque \\
\hline & Usar verniz fosco ou cera \\
\hline \multirow{3}{*}{ Ser seguro } & Usar materiais resistentes \\
\hline & Usar acessórios de boa qualidade \\
\hline & Usar madeiras leves \\
\hline \multirow[b]{2}{*}{ Ter qualidade } & Usar madeira maciça de boa qualidade \\
\hline & $\begin{array}{l}\text { Usar acessórios e ferragens de boa } \\
\text { qualidade }\end{array}$ \\
\hline \multirow{2}{*}{ Ser durável } & Ser de madeira maciça \\
\hline & Ser de madeira resistente \\
\hline \multirow{3}{*}{ Ser confortável } & Possuir medidas adequadas ao usuário \\
\hline & Possuir formas confortáveis ao uso \\
\hline & $\begin{array}{l}\text { Ter acabamento que evite machucados no } \\
\text { usuário }\end{array}$ \\
\hline
\end{tabular}

Fonte: 0 autor (2008)

Pode se observar que as principais necessidades dos consumidores da classe $\mathrm{B} 2 \mathrm{em}$ termos de produto de madeira são bem próximas a dos consumidores da classe $\mathrm{A} 1$, com pequena variação em termos de qualidade e durabilidade.

\section{Conversão das vozes dos consumidores da Classe $\mathrm{C}$ em qualidades exigidas}

A tabela 3 apresenta a conversão das principais necessidades dos consumidores da Classe $\mathrm{C}$ em qualidades exigidas nos produtos de madeira. A avaliação da qualidade pelo cliente refere-se aos aspectos de desemepenho e característica do produto. Nesse caso, a qualidade é avaliada pelo cliente/usuário pela resistência mecânica dos móveis, peso e, principalmente, propriedades organolépticas (cheiro, figura, cor, brilho, rugosidade superficial) e o cojunto forma e funcionalidade.

Tabela 3 - Conversão das vozes dos consumidores em qualidades exigidas Classe $\mathrm{C}$

\begin{tabular}{|c|c|}
\hline NECESSIDADES CLASSE C & QUALIDADES EXIGIDAS CLASSE C \\
\hline \multirow{4}{*}{ Ser bonito } & Usar estilo contemporâneo \\
\hline & Usar forma simples \\
\hline & Usar madeiras escuras \\
\hline & $\begin{array}{l}\text { Usar materiais mesclados como madeira } \\
\text { maciça e vidro }\end{array}$ \\
\hline \multirow{3}{*}{ Ter bom acabamento } & Usar madeira seca para evitar rachaduras \\
\hline & Usar matéria-prima de qualidade \\
\hline & Usar verniz fosco ou cera \\
\hline \multirow{4}{*}{ Ser confortável } & Possuir medidas adequadas ao usuário \\
\hline & Possuir formas confortáveis ao uso \\
\hline & $\begin{array}{c}\text { Ter acabamento que evite machucados no } \\
\text { usuário }\end{array}$ \\
\hline & Usar madeiras leves \\
\hline \multirow{2}{*}{ Ser de baixo custo } & Usar matéria-prima de baixo custo \\
\hline & Custo compatível com o produto \\
\hline \multirow{2}{*}{ Ter qualidade } & Usar madeira maciça \\
\hline & Usar madeira de boa qualidade \\
\hline \multirow{2}{*}{ Ser durável } & Ser de madeira maciça \\
\hline & Usar madeira resistente \\
\hline
\end{tabular}

Fonte: 0 autor (2008)

Quanto às exigências dos consumidores da classe $\mathrm{C}$ variam das demais em termos da exigência de produtos com baixo custo, o que não foi relatado nas classes A1 e B2.

\section{Construção Matriz da Qualidade para geração do projeto conceitual}

Para a construçáo da matriz da qualidade foi utilizado o software QFD Designer 5 da IDEA core para fazer as conversóes entre os dados da tabelas de desdobramento da qualidade exigida e desdobramento das características da qualidade, para tanto foi elaborado um matriz da qualidade para cada classe econômica.

\section{Matriz da Qualidade Classe A1}

A figura 2 apresenta a matriz da casa da qualidade para os consumidores da classe econômica A1 que foi construída com o preenchimento dos dados contidos nas tabelas de desdobramento das qualidades exigidas e tabela das características das qualidades dos produtos. 


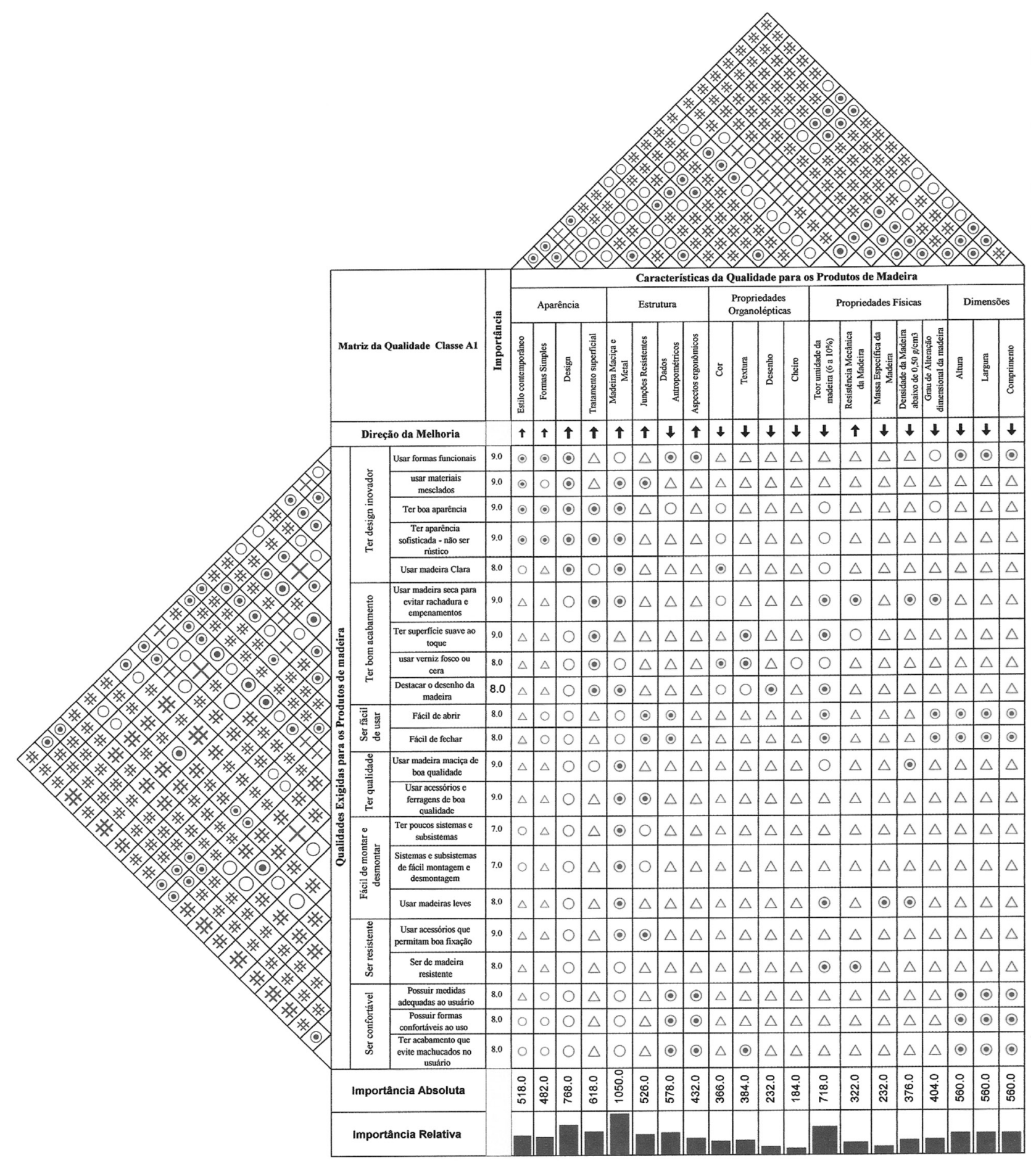

Figura 2 - Matriz QFD / Casa Qualidade Classe A1 Fonte: 0 autor (2008) 
Como citado no item 3.2 os produtos tidos como preferidos para compra pela Classe A1 são: camas, móveis para escritório, mesas para sala de jantar e cadeiras.

A partir da análise da matriz pode se observar que conceitualmente os produtos de madeira destinados à classe A1 devem possuir as seguintes características para serem identificados como um produto de qualidade:

- Ter formas funcionais, formas simples, seguir o estilo contemporâneo e ter design inovador;

- Ser fabricado em madeira maciça e metal e ter tratamento superficial com verniz fosco ou cera, permitindo uma superfície suave ao toque;

- As dimensóes dos componentes devem permitir que o móvel fique leve;

- Atender aspectos ergonômicos como possuir medidas (altura, largura e comprimento) adequadas ao usuário para que o produto seja utilizado confortavelmente;

- Possuir junçóes resistentes para dar segurança ao produto;

- A madeira deve ter teor de umidade entre 16 a $18 \%$ para evitar variação dimensional, rachaduras e empenamentos.

Tais características foram selecionadas entre as que obtiveram os maiores valores relativos (acima de 400 pontos) após preenchimento da matriz.

\section{Matriz da Qualidade Classe B2}

A figura 3 mostra a matriz da casa da qualidade para os consumidores da classe econômica B2 que foi construída com o preenchimento dos dados contidos nas tabelas de desdobramento das qualidades exigidas e tabela das características das qualidades dos produtos.

Como citado no item 3.2 os produtos tidos como preferidos para compra pela classe B2 são: cama, guarda-roupa, cadeira, mesa sala jantar e objetos de decoração.

A partir da análise da matriz pode se observar que conceitualmente os produtos de madeira destinados a classe B2 devem possuir as seguintes características para serem identificados como um produto de qualidade, tais características foram selecionadas entre as que obtiveram os maiores valores relativos (acima de 300 pontos) após preenchimento da matriz:

- Seguir o estilo contemporâneo e ter design diferenciado;

- Ser fabricado em madeira maciça e metal ou vidro e ter tratamento superficial com verniz fosco ou cera permitindo uma superfície suave ao toque;

- As dmensóes dos componentes devem permitir que o móvel fique leve;
- Seguir dados antropométricos e atender aspectos ergonômicos como possuir medidas (altura, largura, comprimento) adequadas ao usuário para que o produto seja utilizado confortavelmente;

- A madeira a ser utilizada deve ser de cor clara, ter o teor de umidade entre 6 a $10 \%$ para evitar variaçáo dimensional, empenamentos e rachaduras.

\section{Matriz da Qualidade Classe C}

A figura 4 mostra a matriz da casa da qualidade para os consumidores da classe econômica $\mathrm{C}$ que foi construída com o preenchimento dos dados contidos nas tabelas de desdobramento das qualidades exigidas e tabela das características das qualidades dos produtos.

Como citado no item 3.2 os produtos tidos como preferidos para compra pela classe $\mathrm{C}$ são: cama, guarda-roupa, cadeira, mesa sala jantar e objetos domésticos

A partir da análise da matriz pode se observar que conceitualmente os produtos de madeira destinados a classe $\mathrm{C}$ devem possuir as seguintes características para serem identificados como um produto de qualidade, tais características foram selecionadas entre as que obtiveram os maiores valores relativos (acima de 300 pontos) após preenchimento da matriz:

- Ter formas funcionais e ter estilo contemporâneo;

- Ser fabricado em madeira maciça e vidro e ter tratamento superficial com verniz fosco ou cera;

- As dimensóes dos componentes devem permitir que o móvel fique leve;

- Atender aspectos ergonômicos como possuir medidas adequadas ao usuário para que o produto seja utilizado com o mínimo de conforto;

- A madeira a ser utilizada deve ser de cor clara, ter o teor de umidade entre 6 a 10\% para evitar variaçáo dimensional.

\section{CONCLUSÕES}

De acordo com os resultados obtidos foi possível chegar às seguintes conclusóes:

A análise das informaçôes mostrou que há pouca variação nas necessidades e desejos por produtos de madeira de acordo com a classe econômica, há produtos que são demandados pelas três classes como camas, mesa para sala de jantar e cadeiras. Produtos como móveis para escritório foram selecionados apenas pela classe $\mathrm{A} 1$, pelo fato de ser a classe que apresenta o maior contingente de profissionais liberais. Produtos como objetos de decoraçáo, foram optados apenas pela classe B2 em decorrência de apresentarem o maior índice de indivíduos separados e estarem iniciando um novo 


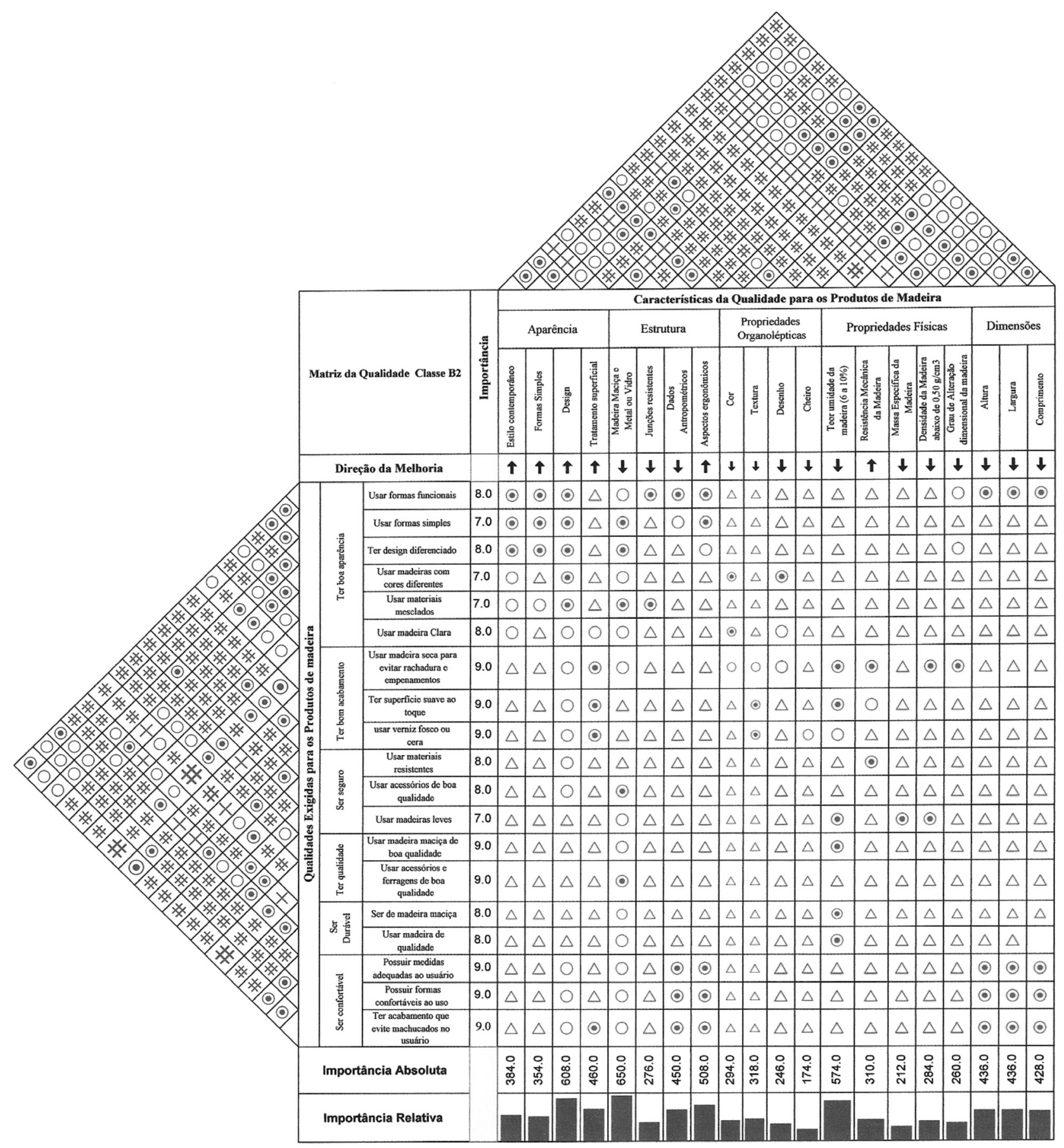

Figura 3 - Matriz QFD / Casa da Qualidade Classe B2

Fonte: 0 autor (2008) 


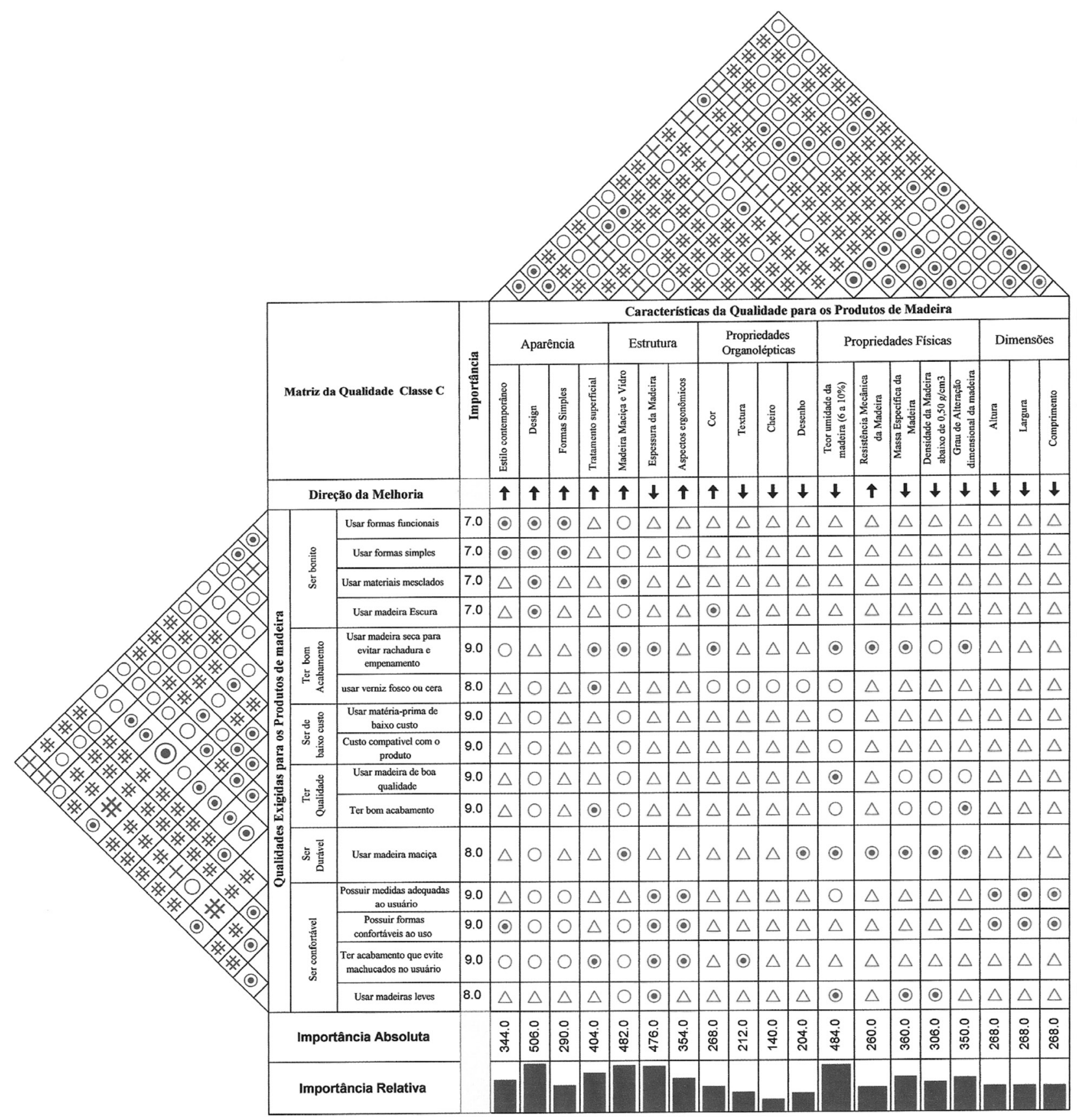

Figura 4 - Matriz QFD / Casa da Qualidade Classe C

Fonte: 0 autor (2008) 
mobiliário. Por outro lado, os objetos de uso domésticos foram citados apenas pelos consumidores da classe $\mathrm{C}$, os que possuem o menor poder de compra.

Quanto às características de qualidade para os produtos das três classes observa-se que os consumidores da classe econômica $\mathrm{A} 1$ são mais exigentes e preferem matéria-prima de qualidade, bom acabamento e design inovador, e estão dispostos a pagar um pouco mais por produtos que tenham um diferencial em termos de design, principalmente em se tratando de produtos de madeira da regiáo Amazônica.

Para os consumidores da classe B2, as principais características que não podem faltar em um produto de madeira é ter bom acabamento e ter design diferenciado.

Os consumidores da classe $\mathrm{C}$ também preferem produtos com bom acabamento e qualidade, mas de baixo custo.

Com base no método QFD, conceitualmente os produtos para atender as preferências das três classes econômicas apresentam pequenas variaçôes. Para a classe A1 os produtos devem ter formas funcionais e simples, seguir o estilo contemporâneo, que é o preferido pelas três classes, e ter design diferenciado - exigência tanto da classe $\mathrm{A} 1$ quanto da classe B2. Para a classe A1 os produtos dever ser fabricado em madeira maciça e metal - já para a classe B2 os produtos devem ser fabricados em madeira maciça e metal ou vidro e para a classe $\mathrm{C}$ os produtos devem ser fabricados a partir de madeira maciça e vidro. Também devem atender aspectos ergonômicos quanto à forma dos produtos, para permitir um uso mais confortável - principalmente para o produto cadeira; a madeira para a fabricação dos produtos deve ser leve, possuir cor clara - a única que exigiu cores escuras foi à classe C. A matéria-prima para a fabricação dos produtos para as três classes devem ter o teor de umidade entre 16 a $18 \%$ para evitar rachaduras e empenamentos nos produtos finais.

Confrontando os resultados da pesquisa, mostrados nas matrizes do método QFD com a realidade do setor em Manaus foi constatado que, independente da classe social, várias exigências não são atendidas. Entre elas a pouca confiabilidade no desempenho do produto, o design pouco atraente, as limitações de capacidades dos processos em cumprir prazos e especificaçôes mínimas de qualidade dos produtos. Os resultados mostram, também que há insatisfação da clientela pelo setor moveleiro, principalmente por parte das lojas que alegam buscar móveis no centro do sul do país devido a qualidade dos produtos e a confiabilidade na entrega.

Por outro lado, os resultados mostram que lojas que atendem as classes superiores disponibilizam móveis que utilizam madeiras da Amazônia, mesmo que produzidos no sul do pais. Nesse caso, a maioria dos entrevistados afirmaram que abasearam as respostas com maior parte dos móveis de alto padrão são confeccionados a partir de madeiras da Amazônia.
Uma menor quantidade, confeccionados a partir de produtos como MDF.

\section{BIBLIOGRAFIA CITADA}

ABIMÓVEL - ASSOCIAÇÃO BRASILEIRA DAS INDÚSTRIAS DO MOBILIÁRIO. Panorama do Setor Moveleiro no Brasil. São Paulo: Abimovel, Junho /2005.

ASSOCIAÇÃO BRASILEIRA DA INDÚSTRIA DE MADEIRA PROCESSADA MECANICAMENTE - ABIMCI. O setor florestal e o segmento de pro dutos de madeira sólida no Brasil. Brasília, 2003.

AMARAL, Daniel Capaldo. et al.Gestão de Desenvolvimento de Produtos: uma referência para a melhoria do processo. São Paulo: Saraiva, 2006.

BAXTER, Mike. Projeto de Produto: guia prático para o design de novos produtos. 2ed. São Paulo: Edgard Blucher, 2000.

CHENG, Lin Chih; MELO FILHO, Leonel Del Rey. QFD Desdobramento da Função Qualidade na gestão de Desenvolvimento de Produtos. São Paulo: Blucher, 2007.

CHENG, Lin Chih. Fundamentos Metodológicos do Método QFD. In: CHENG, Lin Chih; MELO FILHO, Leonel Del Rey. QFD Desdobramento da Função Qualidade na gestão de Desenvolvimento de Produtos. Sáo Paulo: Blucher, p. 489 - 498, 2007.

COUTINHO, Luciano. Design como Fator Competitivo na Indústria Brasileira de Móveis. Campinas: SEBRAE/FINEP/ABIMÓVEL/ FECAMP/UNICAMP/IEL/NEIT, 1999.

GOBE, Antônio Carlos. et al. Gerencia de produtos. São Paulo: Saraiva, 2004.

GORINI, Ana Paula Fontenelle. Panorama do Setor moveleiro no Brasil. BNDES, 2000. 50p.

INSTITUTO BRASILEIRO DE GEOGRAFIA E ESTATÍSTICA. Dados do censo Demográfico no ano de 2000.

PEIXOTO, Manoel Otelino; CARPINETTI, Luis César. Quality Function Deployment - QFD (distribuição da função qualidade. 5th International Symposium on Quality Function Deployment/ I Congresso Brasileiro de Gestão de Desenvolvimento de Produtos, 1999.

PROJETO FLORESTA VIVA. Pesquisa de mercado de móveis em Manaus. Manaus, AM. Junho/2006. Disponível em: <http:// www.florestavivaamazonas.org.br/31.php>. Acesso em 18 abril 2008.

SANTOS, Flávio Anthero dos. O design como diferencial competitivo. Itajai: Univale, 2000.

SILVA, Maria N. P. et al. Diagnóstico do Setor Madeireiro do Médio Amazonas. Manaus: SEBRAE/ AM, 2002.

Recebido em 18/12/2008

Aceito em 09/03/2010 